\title{
Soroprevalência de anticorpos anti-Ehrlichia canis em cães de Cuiabá, Mato Grosso
}

\author{
Seroprevalence anti-Ehrlichia canis antibodies in dogs of Cuiabá, Mato Grosso \\ José Nivaldo da Silva ${ }^{1}$; Arleana do Bom Parto Ferreira de Almeida ${ }^{1}$; Eveline da Cruz Boa Sorte; \\ Agrádia Gonçalves de Freitas²; Luana Gabriela Ferreira do Santos²; Daniel Moura Aguiar; Valéria Régia Franco Sousa ${ }^{3 *}$ \\ ${ }^{1}$ Pós-Graduação em Ciências Veterinárias, Universidade Federal de Mato Grosso - UFMT \\ ${ }^{2}$ Iniciação Científica, Universidade Federal de Mato Grosso - UFMT \\ ${ }^{3}$ Departamento de Clínica Médica Veterinária, Universidade Federal de Mato Grosso - UFMT
}

Recebido em 23 de Novembro de 2009

Aceito em 19 de Janeiro de 2010

\section{Resumo}

A erliquiose canina é uma doença transmitida por carrapatos Rhipicephalus sanguineus e ocasionada pela Ehrlichia canis, bactéria intracelular obrigatória. O presente estudo verificou a prevalência de anticorpos anti-E. canis em 254 cães de quatro regióes administrativas de Cuiabá, Estado de Mato Grosso, por imunofluorescência indireta, observando-se uma prevalência de 42,5\% (108/254) sem diferença significativa entre as regióes. As variáveis idade, raça, sexo, hábitat, acesso à zona rural e presença de carrapatos foram analisadas. Os títulos de anticorpos variaram entre $1: 40$ a 1:2.560. Somente $32(29,63 \%)$ cães soropositivos estavam infestados por carrapatos, todos $R$. sanguineus. O resultado encontrado confirma que não há predisposição racial, sexual ou etária, enquanto a menor ocorrência de cães reagentes no intradomicílio provavelmente está relacionada à baixa infestação por carrapato, apesar de não ter sido observada diferença significativa entre os cães com ou sem a infestação com o carrapato vetor.

Palavras-chave: Ehrlichia canis, imunofluorescência indireta, Cuiabá, inquérito epidemiológico.

\begin{abstract}
Canine ehrlichiosis is a disease transmitted by ticks Rhipicephalus sanguineus and caused by Ehrlichia_canis, obligatory intracellular bacteria. The present study examined the prevalence of anti-E. canis in $254 \mathrm{dogs}$ from four administrative regions of Cuiabá, Mato Grosso, by indirect immunofluorescence assay. There was a prevalence of 42.5\% (108/254) without significant difference between the studied regions. The variables age, breed, sex, habitat, access to rural and ticks were analyzed. The antibody titers ranged from 1:40 to 1:2,560. Only 32 (29.63\%) seropositive dogs were infested with ticks, all $R$. sanguineus. The results confirm that do not have breed, sex or age predisposition to ehrlichiosis due E. canis, while the lowest occurrence of reactive dogs indoors probably related to low tick infestation, although no significant difference between dogs with or without infestation with the tick vector.
\end{abstract}

Keywords: Ehrlichia canis, indirect immunofluorescence, Cuiaba, epidemiological survey.

\section{Introduçáo}

A erliquiose é uma doença de distribuição cosmopolita transmitida pelo carrapato, Rhipicephalus sanguineus, causada por bactérias do gênero Ehrlichia. A Ehrlichia canis é o agente etiológico da erliquiose monocítica canina, sendo um parasito intracelular obrigatório de células hematopoiéticas maduras ou imaturas, especialmente do sistema fagocitário mononuclear (DUMLER et al., 2001).

\footnotetext{
*Autor para correspondência: Valéria Régia Franco Sousa Professora Adjunta, Departamento de Clínica Médica Veterinária, Universidade Federal de Mato Grosso - UFMT, Av. Fernando Correa da Costa, S/N, Bairro Boa Esperança, CEP 78060 900, Cuiabá - MT, Brasil; e-mail: regia@ufmt.br
}

A primeira descrição da E. canis foi infectando um cão Pastor Alemão, na Argélia, por Donatien e Lestoquard, em 1935. O primeiro relato da presença de E. canis, no Brasil, ocorreu em Belo Horizonte, Minas Gerais, por Costa et al. (1973), sendo o segundo em Jaboticabal, São Paulo, em 1978 (KAVINSKI, 1988).

A patogênese da erliquiose monocítica canina envolve três fases consecutivas: a) aguda, b) assintomática persistente, também denominada fase subclínica e c) crônica. A apresentação dos sinais clínicos pode variar, de acordo com as fases, sendo com frequência observada letargia, anorexia, febre, linfoadenomegalia, esplenomegalia, trombocitopenia, distúrbios hemorrágicos e hipergamaglobulinemia (HARRUS et al., 2002). 
O diagnóstico da erliquiose é baseado na combinação dos sinais clínicos, anormalidades hematológicas, achados citológicos e sorológicos, sendo mais recentemente a reação em cadeia da polimerase incorporada ao plano diagnóstico (NEER; HARRUS, 2006). A observação microscópica de esfregaços sanguíneos submetidos à coloração do tipo Romanowsky é simples, barata e fornece um registro permanente (FRITZ, 2009); no entanto a sua sensibilidade é baixa, em torno de 4 a $5 \%$ dos casos na fase aguda (HARRUS et al., 1997; MENESES et al., 2008).

As bactérias do gênero Ehrlichia sp. induzem resposta humoral específica, base para o diagnóstico sorológico (RIKIHISA, 1991), ocorrendo soroconversão nos animais logo após a infecção (OTRANTO et al., 2009). Dentre os testes sorológicos, a Imunofluorescência Indireta é utilizada no diagnóstico da erliquiose, sendo aplicável tanto para estudos de infecçóes experimentais quanto epidemiológicos. Os antígenos utilizados são procedentes do cultivo de células infectadas com E. canis, havendo detecção de anticorpos precoces em até sete dias pós-infecção, embora a maioria dos cães se tornam soropositivos após 28 dias da infecção (HARRUS et al., 1997).

A erliquiose tem sido motivo de grande interesse tanto para pesquisas em medicina veterinária quanto para saúde pública, em decorrência das recentes descobertas de infecção em humanos (STICH et al., 2008); portanto, este trabalho teve o propósito de verificar a soroprevalência da infecção por Ehrlichia canis em cáes domiciliados na cidade de Cuiabá, Estado de Mato Grosso, por meio da imunofluorescência indireta.

\section{Material e Métodos}

\section{Local e periodo do estudo}

O presente estudo foi realizado em Cuiabá (Figura 1), capital do Estado de Mato Grosso, no período de setembro de 2007 a abril de 2009. O município de Cuiabá possui área de $3.538,17 \mathrm{~km}^{2}$, correspondendo $254,57 \mathrm{~km}^{2}$ de área urbana e $3.283,60 \mathrm{~km}^{2}$ de área rural. Localizado na mesorregião Centro-Sul Mato-grossense, possui como coordenadas geográficas de $15^{\circ} 35^{\prime} 56^{\prime \prime} \mathrm{S}$ e $56^{\circ} 06^{\prime} 01^{\prime \prime} \mathrm{O}$ (SILVA et al., 2008).

A região é cercada por três biomas: a Amazônia, o Cerrado e o Pantanal, sendo de clima tropical, quente e úmido.

\section{Cães amostrados}

Os cálculos para obtenção da amostragem dos cães foram definidos pelo programa EpiInfo 3.3.2 (CDC, EUA), considerando-se a proporçáo de cães em relação ao homem de 7:1, com uma prevalência de 20\% (LABARTHE et al., 2003), e um intervalo de confiança de $95 \%$ e erro aceitável de $5 \%$.

Foram incluídas no estudo amostras provenientes de cães das regióes Leste (61 amostras); Norte (68 amostras); Sul (54 amostras) e Oeste (71 amostras), totalizando 254 amostras.

Os cães avaliados eram provenientes de ambientes urbanos domiciliados, de idade e raças variadas e ambos os sexos. Foram obtidas informaçóes contendo identificação, sinais clínicos apresentados no momento da avaliação clínica nas residências, e de presença de carrapatos. As amostras de sangue foram colhidas de forma asséptica, por venopunção cefálica ou jugular, de onde foram obtidos os soros após retração do coágulo e conservadas a $-20{ }^{\circ} \mathrm{C}$ até o momento da prova sorológica.

Os carrapatos presentes nos cáes no momento do inquérito foram colhidos e identificados conforme gênero e espécie, segundo Aragão e Fonseca (1961).

\section{Imunofluorescência indireta}

A imunofluorescência indireta foi realizada a partir das células DH82 infectadas com o isolado São Paulo de E. canis, fixadas em lâminas de imunofluorescência, como descrito por RISTIC et al. (1972). Os soros dos cães foram testados a partir da diluição de 1:40 até 1:2560 (HARRUS et al., 1997; McBRIDE et al., 2001) em solução salina tamponada (PBS) pH 7,2, a 1\% de soro albumina bovina. Para marcação do anticorpo, utilizou-se conjugado de coelho anti-IgG de cão $\left(\mathrm{SIGMA}^{\oplus}\right)$ na diluição 1:400. As lâminas foram examinadas em microscópio de epifluorescência (marca LEICA $^{\oplus}$ ). Em cada lâmina foram incluídos controles negativos e positivos. A amostra foi considerada reagente quando apresentou fluorescência à diluição igual ou maior a 1:40.

\section{Análise estatística}

Para avaliar as associaçôes entre diferentes variáveis, utilizou-se o Teste do Quiquadrado $\left(\chi^{2}\right)$ corrigido por Yates, ou Exato de Fisher, quando algum valor esperado foi igual ou inferior a 5 . Considerou-se o valor de $\mathrm{p} \leq 0,05$ estatisticamente significativo.

\section{Resultados}

A prevalência de cães soropositivos para $E$. canis nos bairros das regiôes administrativas de Cuiabá, Mato Grosso, foi de $42,5 \%$ (108/254). Esse resultado, quando comparado entre as regióes, não apresentou diferença significativa ( $p>0,05$; Tabela 1$)$.

Não foi observada associação significativa $(p>0,05)$ entre o resultado sorológico e as variáveis estudadas: sexo, faixa etária, acesso à rua ou à zona rural e raças (Tabela 2). Os cães sem raça definida (46) representaram $(42,6 \%)$ dos estudados e os de raças puras 62 (57,4\%), dentre eles, Poodle (16), Pitbull (11), Pinscher (10),

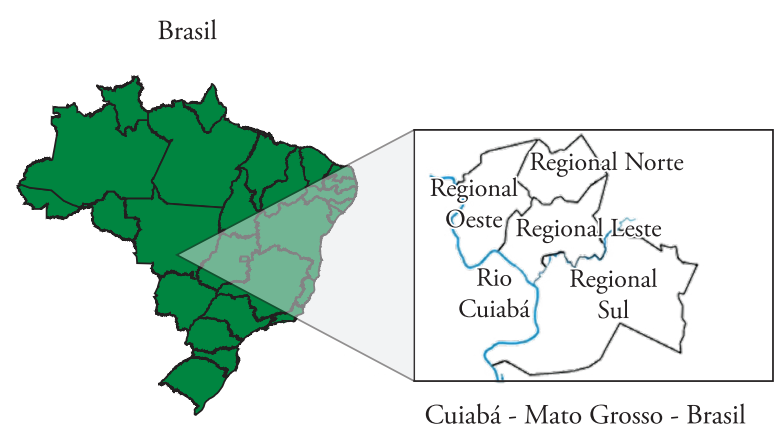

Figura 1. Localização geográfica das regionais administrativas estudadas do município de Cuiabá na América do Sul. 
Dachshund (6), Boxer (4), Rotweiller (4), Dogue alemão (3), Dobermam (2) e Labrador, Pastor alemão, Pointer, Pequinês, Akita e Shitzu um cada.

Com relação ao ambiente de maior permanência do cão, foi observada menor frequência de anticorpos, nos animais com acesso ao intradomicilio $\left(\chi^{2}=9,428 ; \mathrm{p}<0,05\right)$. Dos 254 animais avaliados, apenas $32(12,6 \%)$ apresentaram infestação por carrapatos $R$. sanguineus, $\left(\chi^{2}=5,87, \mathrm{p}=0,118\right)$. Destes, quinze $(46,87 \%)$ sororreagiram à imunofluorescência indireta (Tabela 2).

Diversas alteraçôes clínicas foram observadas em 31 dos cães sororreagentes, incluindo linfadenopatia (2), emagrecimento (2), petéquias (2), apatia (1), hepatomegalia (1), esplenomegalia (1), além dos sinais oftálmicos (9), nervosos (1) e dermatológicos (20).

A proporção dos títulos apresentados pelos cães na técnica de imunofluorescência indireta foi: 40(4,6\%), 80 (5,6\%), 160 (8,3\%), $320(13,9 \%), 640(14,8 \%), 1.280(20,4 \%)$ e $2.560(32,4 \%)$.

\section{Discussão}

A prevalência de E. canis encontrada neste estudo (42\%) em cães domiciliados de Cuiabá foi semelhante à relatada por Aguiar et al. (2007), em município localizado no Estado de Rondônia $(37,9 \%)$, estando acima das relatadas por outros autores no Brasil: 23\% no Paraná (TRAPP et al., 2006) e 36\% na Bahia (CARLOS et al., 2007). Entretanto, foi inferior ao resultado de Almeida e Sousa (2006), que observaram, pelo teste SNAP 3DX, a prevalência de $60 \%$ em cães atendidos em hospital do mesmo município.

A prevalência de $E$. canis está largamente associada à distribuição do vetor, encontrado principalmente em regióes tropicais e subtropicais (RODRIGUEZ-VIVAS; ALBORNOZ; BOLIO, 2005). No Brasil, diferentes prevalências são perceptíveis nos Estados do Nordeste e do Sul, relacionando-se a uma melhor adaptação e, consequentemente, ao maior número de carrapatos em clima quente e úmido do que em clima temperado. No município estudado, a alta prevalência é similar a outras áreas da região Centro-oeste e Nordeste (LABARTHE et al., 2003). Outros fatores epidemiológicos que interferem na percentagem de animais sororreagentes são: tipo de amostragem, tamanho das amostras utilizadas nos estudos e sensibilidade dos testes (CARLOS et al., 2007), além do comportamento do animal e faixa etária média da população estudada (RODRIGUEZ-VIVAS; ALBORNOZ; BOLIO, 2005)

Não foi observada associação entre a taxa de infecção e a faixa etária, corroborando Aguiar et al. (2007), no Brasil, e Rodriguez-Vivas; Albornoz; Bolio (2005) no México. No entanto, neste estudo, cães com idade entre 3 a 6 anos tiveram maior soroprevalência, justificada pelo estado imunológico do hospedeiro ou exposição ao carrapato por longo período (RODRIGUEZ-VIVAS; ALBORNOZ; BOLIO, 2005).

Não foi observada predisposição racial e sexual quanto à infecção por E. canis na cidade de Cuiabá, igualmente como visto por Sousa (2006). No entanto, maior severidade clínica da erliquiose é descrita em cães da raça Pastor Alemão, não havendo predisposição dessa raça à infecção (HARRUS et al., 1997). As alteraçóes clínicas observadas nos cães com infecção por $E$. canis são condizentes com o estudo realizado por Ueno et al. (2009) em cães atendidos em hospital veterinário; contudo, neste estudo, observou-se a maioria dos animais assintomáticos, por se tratar de inquérito epidemiológico.
Tabela 1. Prevalência de anticorpos anti-Ehrlichia canis, em cães do município de Cuiabá, MT, segundo os bairros estudados.

\begin{tabular}{ccccc}
\hline $\begin{array}{c}\text { Bairro } \\
\text { estudado }\end{array}$ & $\begin{array}{c}\text { No cáes } \\
\text { avaliados }\end{array}$ & $\begin{array}{c}\text { Positivos } \\
\text { Prevalência* } \\
(\mathbf{\%})\end{array}$ & IC - 95\% \\
\hline $\begin{array}{c}\text { Jardim } \\
\text { Universitário }\end{array}$ & 61 & 23 & 37,7 & $(26,20-50,31)$ \\
Cidade Alta & 71 & 37 & 52,1 & $(40,50-63,50)$ \\
$\begin{array}{c}\text { Coophema } \\
\text { Morada do } \\
\text { Ouro }\end{array}$ & 54 & 25 & 46,29 & $(33,36-59,60)$ \\
\hline Total & 68 & 23 & 33,82 & $(23,30-45,60)$ \\
\hline${ }^{*} \mathrm{p}>0,05$ & & 108 & 42,5 & $(36,50-48,60)$ \\
\hline
\end{tabular}

Tabela 2. Frequência (\%) e valor de Quiquadrado $\left(\chi^{2}\right)$ dos cães amostrados e reagentes à Imunofluorescência Indireta (titulo $\geq 40$ ) contra antígenos de Ehrlichia canis, domiciliados em Cuiabá, MT.

\begin{tabular}{lcccc}
\hline \multirow{2}{*}{ Variáveis } & \multicolumn{5}{c}{ Cáes (\%) } \\
\cline { 2 - 5 } & Amostrados & Reagentes** & $\chi^{\mathbf{2}}$ & $\mathbf{p}$ \\
\hline Macho & 119 & $56(47,1)^{\mathrm{a}}$ & & \\
Fêmea & 135 & $52(38,5)^{\mathrm{a}}$ & 1,55 & 0,212 \\
\hline Faixa etária & 29 & $12(41,4)^{\mathrm{a}}$ & & \\
$\leq 1$ & 78 & $28(35,9)^{\mathrm{a}}$ & & \\
$\geq 1$ - 3 & 71 & $33(46,5)^{\mathrm{a}}$ & & \\
$\geq 3$ - 6 & 72 & $32(44,5)^{\mathrm{a}}$ & 0,775 & 0,378 \\
$\geq 6$ & 4 & $3(75)$ & & \\
Indeterminado & 101 & $46(45,54)^{\mathrm{a}}$ & & \\
\hline Sem Raças Definidas (SRD) & 153 & $62(40,52)^{\mathrm{a}}$ & 0,44 & 0,50 \\
Cáes de raças puras & 135 & $59(43,7)^{\mathrm{a}}$ & & \\
\hline Sem acesso à rua & 119 & $49(41,2)^{\mathrm{a}}$ & 0,08 & 0,777 \\
Acesso livre à rua & 13 & $1(7,7)^{\mathrm{a}}$ & & \\
\hline Intradomić́lio & 35 & $11(31,4)^{\mathrm{ab}}$ & & \\
Peridomić́lio & 206 & $96(46,6)^{\mathrm{b}}$ & 9,428 & 0,002 \\
Intra e Peridomicílio & 19 & $9(47,4 \%)^{\mathrm{a}}$ & \\
\hline Acesso à zona rural & 235 & $99(42,1)^{\mathrm{a}}$ & 0,04 & 0,838 \\
Sem acesso à zona rural & &
\end{tabular}

${ }^{*}$ Letras diferentes na coluna indicam $\mathrm{p}<0,05$; ${ }^{* *}$ Letras iguais na coluna indicam $\mathrm{p}>0,05$.

Quanto ao ambiente de maior permanência dos cães, demonstrou-se menor frequência $(\mathrm{p}<0,05)$ da infecção por $E$. canis nos com acesso apenas ao intradomicilio, o que provavelmente é justificado pela menor ocorrência de parasitismo por $R$. sanguineus, possivelmente pela convivência muito próxima com seus proprietários levando-os a zelar pelo controle de ectoparasitos (LABRUNA; PEREIRA, 2001).

Não foi observada diferença significativa entre os cães com livre acesso à rua e/ou com acesso à zona rural. De acordo com Carlos et al. (2007), o ambiente rural, cuja situação socioeconômica dificulta o controle do vetor com os cães facilmente infestados por carrapatos, apresenta maior risco de infecção (RODRIGUEZ-VIVAS; ALBORNOZ; BOLIO, 2005), aspecto não observado nesta pesquisa, já que os cães amostrados frequentavam esporadicamente essas áreas.

Segundo Trapp et al. (2006), o parasitismo por $R$. sanguineus tem sido apontado como principal fator de risco para a erliquiose monocítica canina. Das amostras de carrapatos coletadas nos cães pesquisados, todas foram identificadas como dessa espécie. De 
acordo com Labruna e Pereira (2001), esse carrapato encontra-se preferencialmente em regióes urbanas do país, porém também em menores densidades nas áreas rurais e, provavelmente, em todo o território nacional, corroborando este estudo. Estes mesmos autores descrevem reduzida infestação canina por carrapatos em determinadas estaçóes do ano, em que apenas 5\% da populaçáo é encontrada no hospedeiro, enquanto $95 \%$ estariam no ambiente nas fases de vida livre, o que justificaria o encontro de poucos cáes parasitados na coleta.

Nesse inquérito, observou-se elevada prevalência de anticorpos anti-E. canis em cães domiciliados em Cuiabá, Estado de Mato Grosso, apesar da baixa infestação por carrapatos encontrada no momento da pesquisa e elevado número de cães assintomáticos, evidenciando o aspecto subclínico dessa infecção e a ampla distribuição do agente no município.

\section{Referências}

AGUIAR, D. M. et al. Prevalence of Ehrlichia canis (Rickettsiales: Anaplasmataceae) in dogs and Rhipicephalus sanguineus (Acari: Ixodidae) ticks from Brazil. Journal of Medical Entomology, v. 44, n. 1, p. 126-132, 2007.

ALMEIDA, A. B. P. F.; SOUSA, V. R. F. Análise sorológica e biomolecular da infecção por Ehrlichia canis. Ciência Animal Brasileira, supl. 1, p. 265-267, 2006.

ARAGAO, H.; FONSECA, F. Notas de Ixodologia. VIII Lista e chave para os representantes da fauna ixodológica brasileira. Memórias do Instituto Oswaldo Cruz, v. 59, n. 2, p. 115-129, 1961.

CARLOS, R. S. et al. Frequência de anticorpos anti-Erhlichia canis, Borrelia burgdorferi e antígenos de Dirofilaria immitis em cães na microrregião Ilhéus-Itabuna, Bahia, Brasil. Revista Brasileira de Parasitologia Veterinária, v. 16, n. 3, p. 117-120, 2007.

COSTA, J. O. et al. Ehrlichia canis infection in dog in Belo Horizonte, Brazil. Arquivo da Escola de Veterinária da Universidade Federal de Minas Gerais, v. 25, p. 199-200, 1973.

DUMLER, J. S et al. Reorganization of genera in the families Rickettsiaceae and Anaplasmataceae in the order Rickettsiales: unification of some species of Ehrlichia with Anaplasma, Cowdria with Ehrlichia and Ehrlichia with Neorickettsia, descriptions of six new species combinations and designation of Ehrlichia equi and 'HGE agent' as subjective synonyms of Ehrlichia phagocytophila. International Journal of Systematic and Evolutionary Microbiology, v. 51, n. 6, p. 2145-2165, 2001.

FRITZ, C. L. Emerging tick-borne diseases. Veterinary Clinics of North America: Small Animal Practice, v. 39,n. 2, p. 265-278, 2009.

HARRUS, S. et al. Comparison of three enzyme-linked immunosorbant assays with the indirect immunofluorescent antibody test for the diagnosis of canine infection with Ehrlichia canis. Veterinary Microbiology, v. 86, n. 4, p. 361-368, 2002.

HARRUS, S. et al. Canine monocytic ehrlichiosis: a retrospective study of 100 cases, and an epidemiological investigation of prognostic indicators for the disease. Veterinary Record, v. 141, n. 14, p. 360-363, 1997.
KAVINSKI, L. C. Ocorrência de um caso de erliquiose canina em Curitiba - PR. Revista do Setor de Ciências Agrárias, v. 10, n. 1-2, p. 217-219, 1988.

LABARTHE, N. et al. Serologic prevalence of Dirofilaria immitis, Ehrlichia canis, and Borrelia burgdorferi infections in Brazil. Veterinary Therapeutics, v. 4, n. 1, p. 67-75, 2003.

LABRUNA, M. B.; PEREIRA, M. C. Carrapato em cães no Brasil. Clínica Veterinária, v. 30, p. 24-31, 2001.

McBRIDE, J. W et al. Immunodiagnosis of Ehrlichia canis infection with recombinant proteins. Journal of Clinical Microbiology, v. 39, n. 1, p. 315-322, 2001.

MENESES, I. D. S. et al. Perfil clínico-laboratorial da erliquiose monocítica canina em cães de Salvador e região metropolitana, Bahia. Revista Brasileira de Saúde e Produçáo Animal, v. 9, n. 4, p. 770-776, 2008.

NEER, T. M.; HARRUS, S. Canine monocytotropic ehrlichiosis and neorickettsiosis (E. canis, E. chaffeensis, E. ruminantium, N. sennetsu, and $N$. risticii infections). In: GREENE, C. E. Infectious Diseases of the Dog and Cat. Saint Louis: Saunders Elsevier, 2006. p. 203-216.

OTRANTO, D.; DANTAS-TORRES, F.; BREITSCHWERDT, E. B. Managing canine vector-borne diseases of zoonotic concern: part one. Trends in Parasitology, v. 25, n. 4, p. 157-163, 2009.

RIKIHISA, Y. The tribe Ehrlichieae and ehrlichial diseases. Clinical Microbiology Reviews, v. 4, n. 3, p. 286-308, 1991.

RISTIC, M. et al. Serological diagnosis of tropical canine pancytopenia by indirect immunofluorescence. Infection and Immunity, v. 6, n. 3, p. 226-231, 1972.

RODRIGUEZ-VIVAS, R. I.; ALBORNOZ, R. E. F.; BOLIO, G. M. E. Ehrlichia canis in dogs in Yucatan, Mexico: seroprevalence, prevalence of infection and associated factors. Veterinary Parasitology, v. 127, n. 1, p. 75-79, 2005.

SILVA, W. T. P. et al. Quota per capita de água, fatores intervenientes e modelagem: estudo de caso para classes socioeconômicas de Cuiabá-MT. Sociedade \& Natureza, v. 20, n. 2, p. 219-230, 2008.

STICH, R. W. et al. Host surveys, ixodid tick biology and transmission scenarios as related to the tick-borne pathogen, Ehrlichia canis. Veterinary Parasitology, v. 158, n. 4, p. 256-273, 2008.

SOUSA, V. R. F. Avaliação clínica, morfológica, hematológica, bioquímica e biomolecular de cáes naturalmente infectados por Ehrlichia canis e Anaplasma platys. 2006. 46 f. Tese (Doutorado) Universidade Federal Rural do Rio de Janeiro, Rio de Janeiro, 2006.

TRAPP, S. M et al. de. Seroepidemiology of canine babesiosis and ehrlichiosis in a hospital population. Veterinary Parasitology, v. 140, n. 3-4, p. 223-230, 2006.

UENO, T. E. H. et al. Ehrlichia canis em cães, atendidos em hospital veterinário de Botucatu, Estado de São Paulo, Brasil. Revista Brasileira de Parasitologia Veterinária, v. 18, n. 3, p. 57-61, 2009. 